The University of Maine

\title{
DigitalCommons@UMaine
}

Electronic Theses and Dissertations

Fogler Library

Spring 5-11-2018

\section{Improving Techniques to Study Equine Cervical Mucociliary Clearance}

Melissa A. Hawkes

University of Maine, melissa.hawkes@maine.edu

Follow this and additional works at: https:// digitalcommons.library.umaine.edu/etd

8 Part of the Animal Structures Commons, Cells Commons, Large or Food Animal and Equine Medicine Commons, Other Animal Sciences Commons, Urogenital System Commons, and the Veterinary Anatomy Commons

\section{Recommended Citation}

Hawkes, Melissa A., "Improving Techniques to Study Equine Cervical Mucociliary Clearance" (2018). Electronic Theses and Dissertations. 2859.

https://digitalcommons.library.umaine.edu/etd/2859 


\title{
IMPROVING TECHNIQUES TO STUDY EQUINE \\ CERVICAL MUCOCILIARY CLEARANCE
}

\author{
By \\ Melissa Hawkes \\ B.S. University of Maine, 2016 \\ A THESIS \\ Submitted in Partial Fulfillment of the \\ Requirements for the Degree of \\ Master of Science \\ (in Animal Sciences)
}

The Graduate School

The University of Maine

May 2018

Advisory Committee:

Robert Causey, Professor of Animal and Veterinary Science, Advisor

Martin Stokes, Professor of Animal and Veterinary Science

Mary Tyler, Professor of Zoology 
Copyright 2018 Melissa Hawkes 


\title{
IMPROVING TEHCNIQUES TO STUDY EQUINE
}

\section{CERVICAL MUCOCILIARY CLEARANCE}

\author{
By Melissa Hawkes
}

Thesis Advisor: Dr. Robert Causey

An Abstract of the Thesis Presented

in Partial Fulfillment of the Requirements for the Degree of Master of Science

(in Animal Sciences)

May 2018

Bacterial uterine infections inflict major losses on the equine breeding industry. These infections usually arise from bacteria introduced at breeding. Micro-currents propelled by ciliated cells between the folds of the uterus and cervix have been proposed as a means by which contaminants are expelled. Previous data have shown possible ciliary micro-currents propelling carbon particles, occasionally rotating, through cervical folds. However, adherence to the epithelium may have interfered with movement of carbon in these studies. Therefore, we tested potentially non-adherent substances to reveal ciliary micro-currents on the equine cervix under high magnification video-endoscopy. We hypothesized that polyethylene green microspheres 1 - $5 \mu \mathrm{m}$ and $70 \mu \mathrm{m}$ in diameter, would be superior to carbon in revealing micro-currents on the cervical epithelium and that $70 \mu \mathrm{m}$ hemispherically coated bichromal microspheres would display rotation. A suspension containing these microspheres and carbon was deposited onto the cervix of 5 estrous mares and movement of each type of particle was recorded under high video endoscopy for approximately 10 - 20 minutes. In more than $50 \%$ of each video recording the field of view was obscured by camera movement or poor positioning. However, the remainder of the recording contained short segments in which the interactions between the epithelium and particles were observable. All observable segments were then analyzed for the presence or absence of desired (visibility, motion, and rotation) and undesired (aggregation) criteria for each type of particle. Particles were scored for the prevalence of these desired and undesired criteria according to the number of video segments in which they were observed. Data were analyzed by the Kruskal-Wallis test. Backward rotation of bichromal spheres was interpreted as evidence of ciliary activity. Overall, carbon scored equal to or higher than the microspheres, leading to rejection of the hypothesis. Of the 
microspheres, the bichromal microspheres scored highest overall, but tended to aggregate more than the green microspheres, aggregation being undesirable. Subjective assessment concluded that cervical movement was closely related to respiratory movements of the mare, and that the constantly moving cervical folds helped clear the deposited particles. These data may improve detection of mucociliary clearance in the cervix and uterus and may assist future studies to detect impaired mucociliary clearance in infertile mares. 


\section{ACKNOWLEDGEMENTS}

I would like to thank my advisor Dr. Robert Causey for all of his support and guidance throughout this process. Without him I would not be where I am in my knowledge of science. I would also like to thank Dr. Mary Tyler for her constant words of encouragement, and Dr. Martin Stokes for the writing skills he has helped me with over the years.

I would also like to show my appreciation for Alec Toothacker, Anna Richards, and Chelsie Oldfield for all of their assistance over the past two years. Many thanks to all of the individuals that have been present and more than happy to help with horse handling throughout this research. I would also like to thank my family and friends for their support and encouragement. 


\section{TABLE OF CONTENTS}

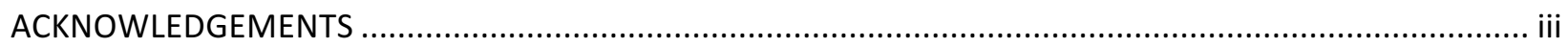

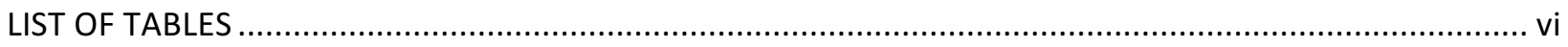

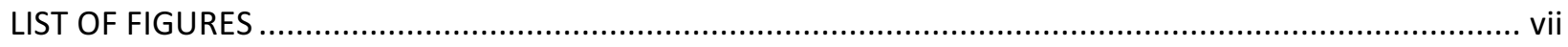

1. INTRODUCTION

1.1. The importance of Cilia and Mucociliary Clearance ....................................................... 2

1.2. Mucociliary Clearance in the Respiratory Tract of Horses .................................................... 3

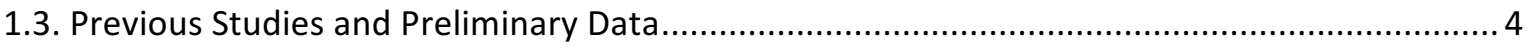

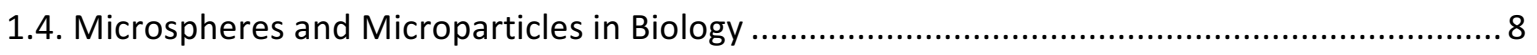

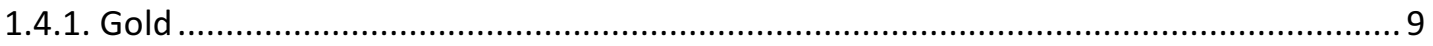

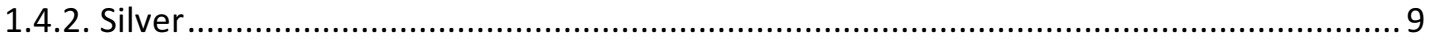

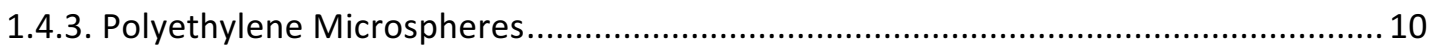

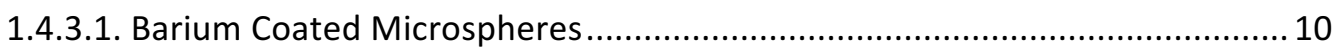

1.4.3.2. Hemispherically coated Bichromal Microspheres ....................................... 10

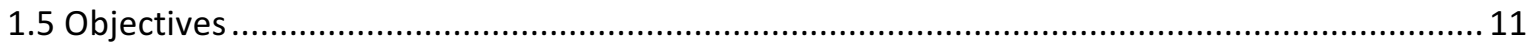

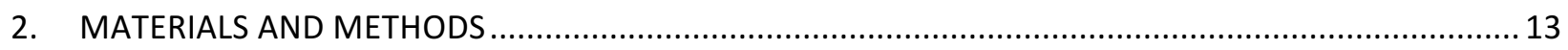

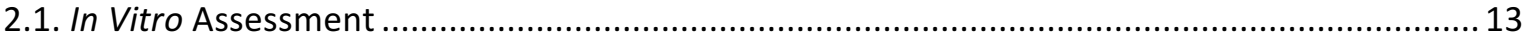

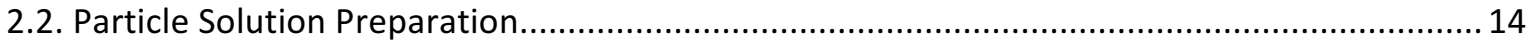

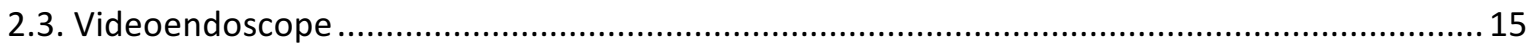

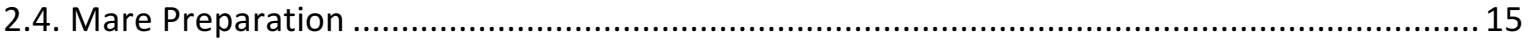

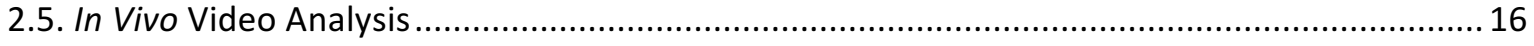

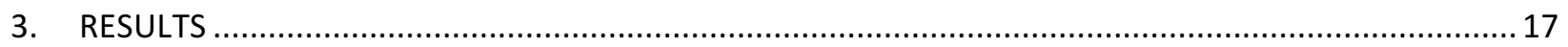

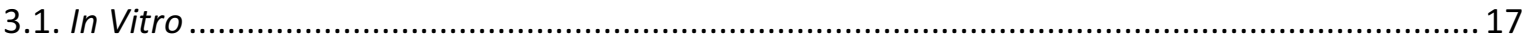

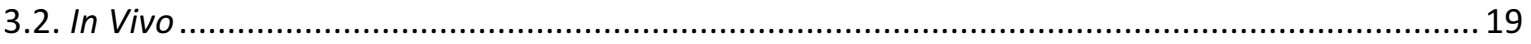




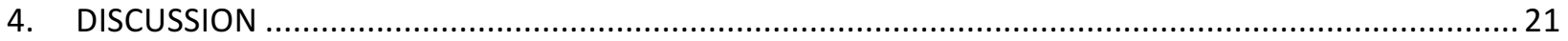

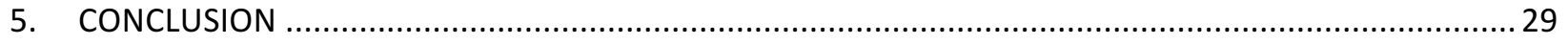

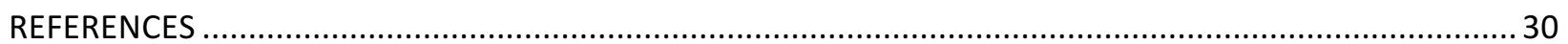

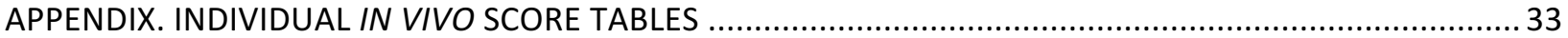

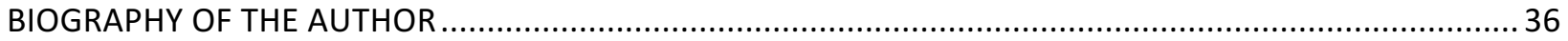




\section{LIST OF TABLES}

Table 1. Assessment guidelines of particles during microscopic and endoscopic portion

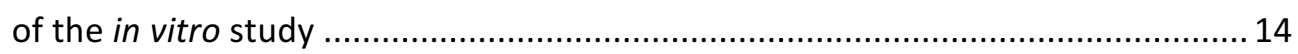

Table 2. Assessment of particles during microscopic and endoscopic portions of the

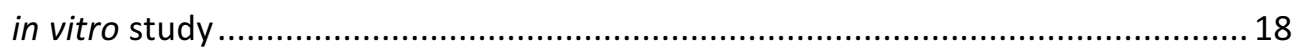

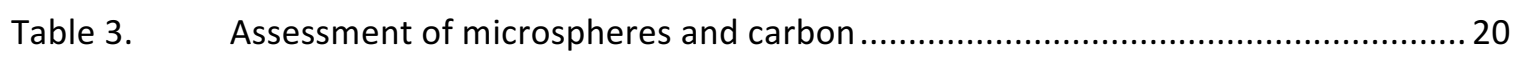

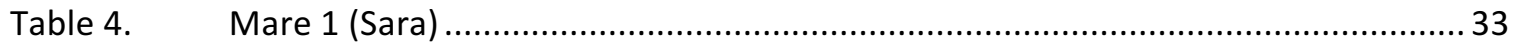

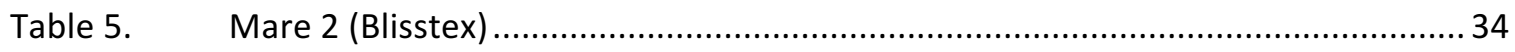

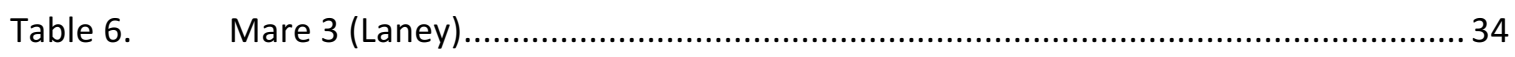

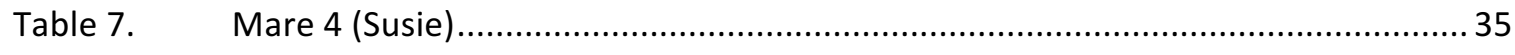

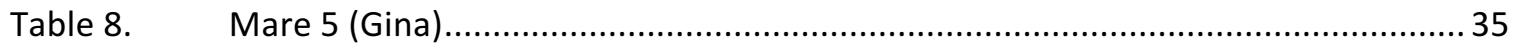




\section{LIST OF FIGURES}

Figure 1. Axoneme: microtubule-based cytoskeleton inside structure of motile cilia and

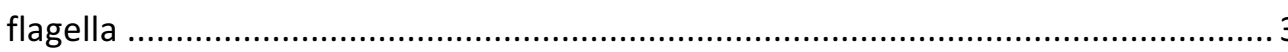

Figure 2. Carbon particle being propelled by ciliated epithelium in vitro .............................. 5

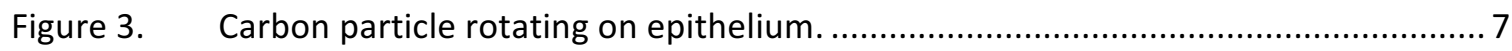

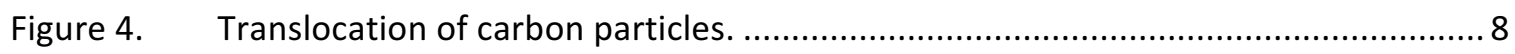

Figure 5. Prediction of two possible types of rotation that may be visible.......................... 11

Figure 6. Appearance of several particles under videoendoscopy ...................................... 19

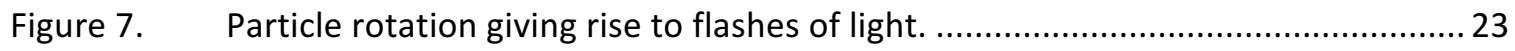

Figure 8. Mucus staining effect of 1-5 $\mu \mathrm{m}$ fluorescent green polyethylene microspheres ...... 25

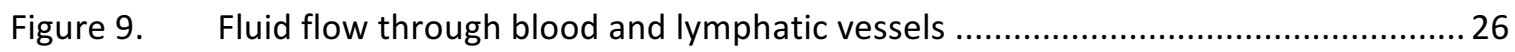

Figure 10. Mucus sheets moving in opposing directions, in an alternating pattern ...............27

Figure 11. Self-clearing of the cervical epithelium in under 10 minutes................................28 


\section{CHAPTER 1}

\section{INTRODUCTION}

Bacterial infections in the uterus of mares are a major cause of losses in the equine breeding industry affecting between $25-60 \%$ of barren mares $(1,4,9)$. These infections usually arise from bacterial contaminants introduced at breeding. The first line of defense against these infections has always been considered phagocytosis by neutrophils. When bacteria are present in the uterus there is indeed an influx of proteins and neutrophils (28). This influx leads to acute inflammation which usually quickly resolves. Most bacteria and inflammatory cells can be expelled from the uterus through uterine contractions. However, if a poor uterine environment persists due to failure to void fluid, neutrophils may show impaired ability to phagocytize bacteria. Because neutrophil function also may be fundamentally impaired in the mucosal immune system of the equine uterus, researchers have therefore questioned the ability of phagocytosis to clear the uterus of all bacteria (22).

Weaker than normal uterine contractions, a uterus that hangs low in the mare's abdomen (often referred to as a pendulous uterus), and abnormal perineal conformation are among the reasons for an increased likelihood of infection and poor intrauterine environment (18). Susceptibility to infections is also correlated with reproductive injury. In post-mortem examinations, it was found that mares who had scarring, hemorrhage, granulation and loss of folds in the reproductive and urinary tract lining, or fibrous tissue around the cervix were more susceptible to infections during their lives (26). Whether these anatomical abnormalities cause increased infections or are a consequence of upregulated inflammatory mediators due to infection remains unclear.

Mucociliary clearance (MCC) is the self-clearing of a mucous membrane by the propulsion of a mucus blanket by ciliated epithelial cells. Mucociliary clearance has been proposed to be a secondary defense against bacteria in the equine genital tract. Observations of a mucus layer resting on ciliated 
cells in uterine biopsies indicate that the key components of a mucociliary apparatus are present (6). In addition, there is extensive longitudinal folding of the uterine and cervical epithelia. Such folds of ciliated epithelium on the equine cervix may increase the efficiency of the mucociliary apparatus, and suggest that micro-currents could be maximized at these sites (12). Currents may assist in removing bacteria, inflammatory cells, and non-viable spermatozoa. Direct visualization of micro currents and mucociliary clearance in live mares is still necessary to understand how the uterus fights infection, and how a dysfunctional mucociliary clearance may impact a mare's reproductive health.

In this study, we sought to optimize in vivo visualization of mucocilary clearance in healthy mares in order to help determine if mucociliary clearance acts as a defense against bacteria.

\subsection{The importance of Cilia and Mucociliary Clearance}

Cilia, the plural of the singular noun cilium, comes from the Latin word for "eyelashes." Cilia are organelles found as extracellular projections on eukaryotic cells (13). They appear as small projections from a larger cell body. There are two types of cilia commonly found in the body, motile cilia and nonmotile, or primary cilia. Primary cilia appear to act solely as a sensory organelle, an example being the dendritic knob of the olfactory neuron where smells are converted into action potentials. Recently, sensory proteins have been identified in motile cilia. These proteins detect fluid flow, bitter taste, and sex hormones (2). Motile cilia and flagella make up a group of organelles referred to as undulipodia (19). Undulipodia are a class of 9+2 organelles, which get their name from the microtubule-based cytoskeleton inside structure of motile cilia and flagella. This structure is referred to as the axoneme. In primary cilia, the axoneme appears as a ring of nine outer microtubule doublets; in motile cilia and flagella there are two addition central microtubule singlets (Figure 1) $(11,24)$. The $9+2$ motile ciliary ultrastructure is conserved throughout the animal kingdom (20). 


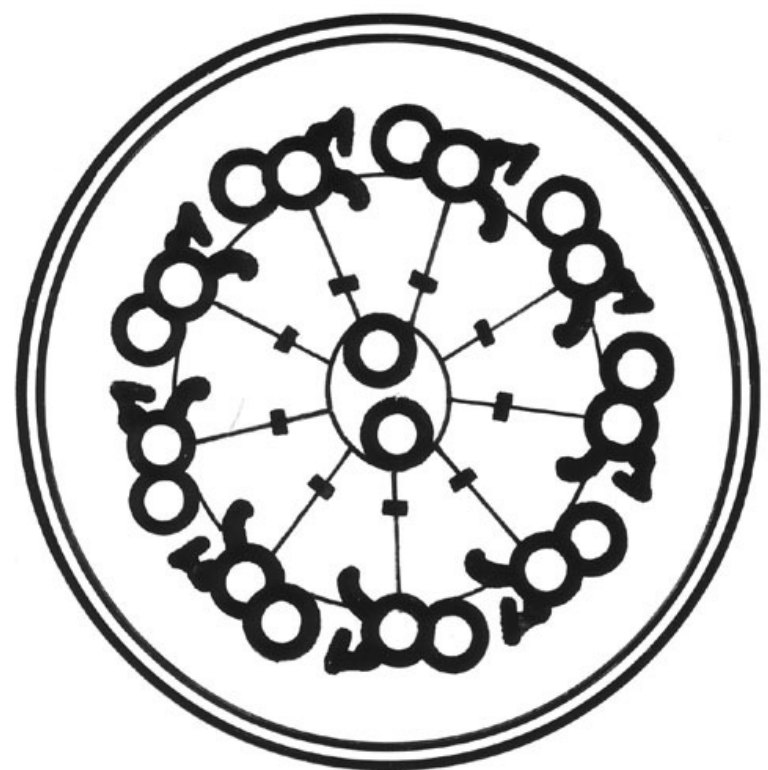

Richard Allen's Image Collection: Chapter 18: Tetrahymena

Figure 1. Axoneme: microtubule-based cytoskeleton inside structure of motile cilia and flagella. Motile cilia 9+2 microtubule-based cytoskeleton. Axoneme are the nine outer microtubule doublets found in all cilia, and the center microtubule singlets found only in motile cilia and flagella.

\subsection{Mucociliary Clearance in the Respiratory Tract of Horses}

Mucociliary clearance is a well-established defense mechanism of the respiratory tract. A disturbance in this process in the respiratory tract of horses (or any mammal) can lead to many diseases, such as pneumonia or chronic sinusitis. When discussing the health of the lungs there is a complex relationship between mucus structure and its propulsion by the airway cilia (10). One of these studies in horses tested the rate at which mucociliary clearance changed when lowering and raising the head. It was found that lowering the head increased movement of mucus, while raising the head slowed movement of mucus and caused a collection of mucus at the bottom of the lungs (23). There have also been studies on the mucociliary clearance of sedated, diseased, and exercised horses to determine how 
the mucociliary clearance rates differ (29). However, scientists have neglected to study other systems where mucociliary clearance may be present, such as the reproductive system.

It is known that bacteria present in the uterus lead to an influx of proteins and neutrophils (27). As mentioned, this influx may lead to inflammation that eventually impedes the phagocytic functions of the neutrophils. Mucus, however, lacks the ability to support phagocytosis during these times of inflammation. Mucociliary clearance therefore may aid in the removal of bacterial and inflammatory cells from the mucosal surface (5). Studies have also shown neutrophil activity is higher in tissues and circulation outside of the uterus, suggesting that neutrophil activity inside the uterus is not the main line of defense, and that bacteria need to be expelled via another route (27). There are many other mechanisms which could contribute to uterine defense but the presence of mucus and cilia on the equine genital tract strongly suggest that mucociliary clearance may play a role.

In live mares, micro-particles may serve as a model for bacteria. Micro-particles have the potential to show the movement of motile cilia, and whether or not they are being trapped in mucus and expelled. This could allow the development of techniques to demonstrate the existence of a functional mucociliary apparatus in the genital tract of the live mare, and serve as a basis for further research.

\subsection{Previous Studies and Preliminary Data}

Early studies showed that when carbon was infused into the uterus it did not adhere to the intact epithelium due to a layer of mucus produced by cells lining the endometrium (7). Subsequent research examined samples of uterine epithelium observed under an inverted microscope, having been obtained in a similar method to a uterine embryo wash. The uterine cells collected showed clear indications of motile cilia, by the rotational movement of floating rafts of epithelial cells with beating cilia (Figure 2). Carbon was added to these dishes to simulate bacteria in the uterus and to better 
visualize ciliary movement. The carbon was chosen due it its visibility and varying size. This study led to examination of mucociliary clearance in the live mare.
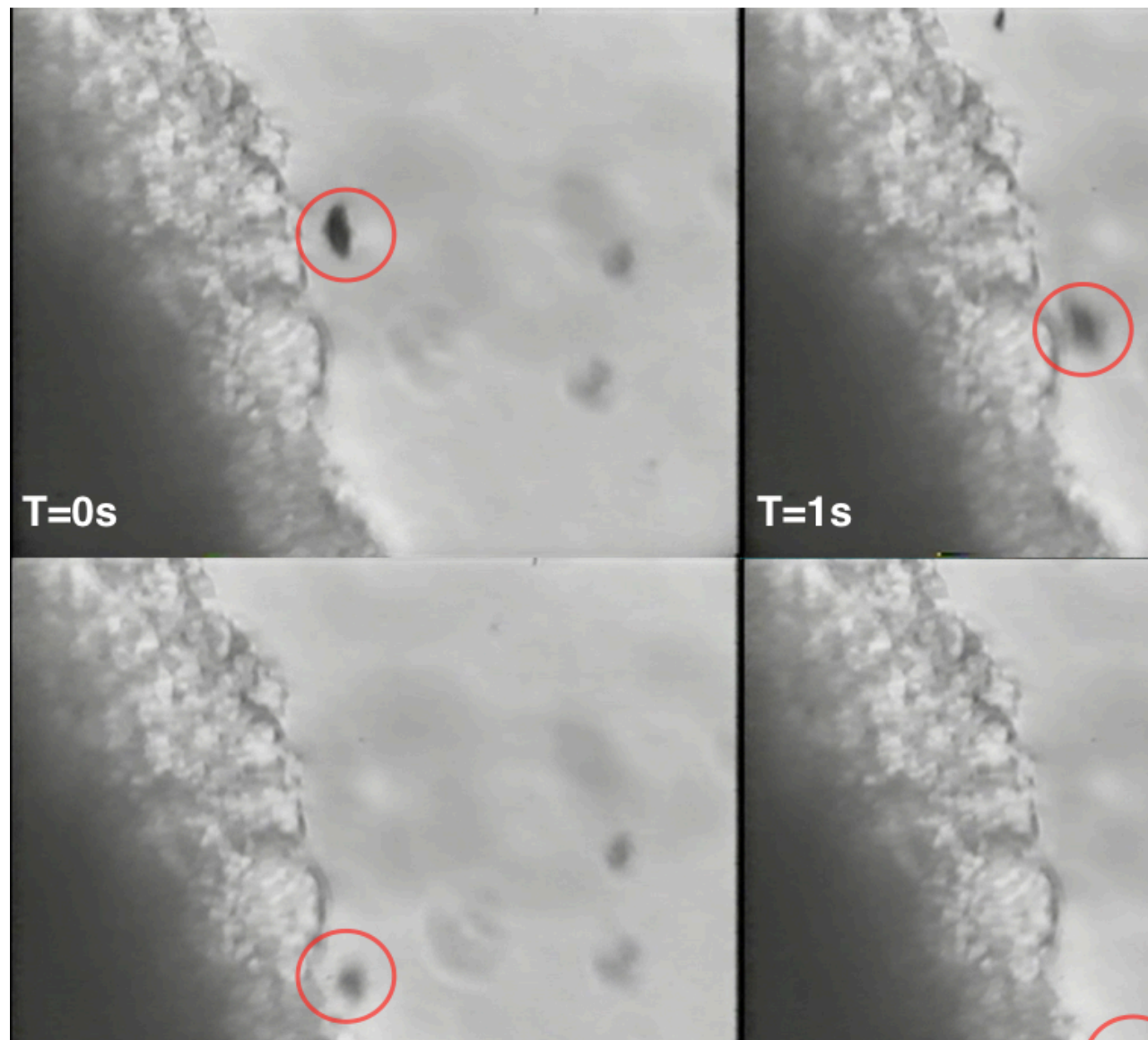

\section{$\mathrm{T}=2 \mathrm{~s}$}

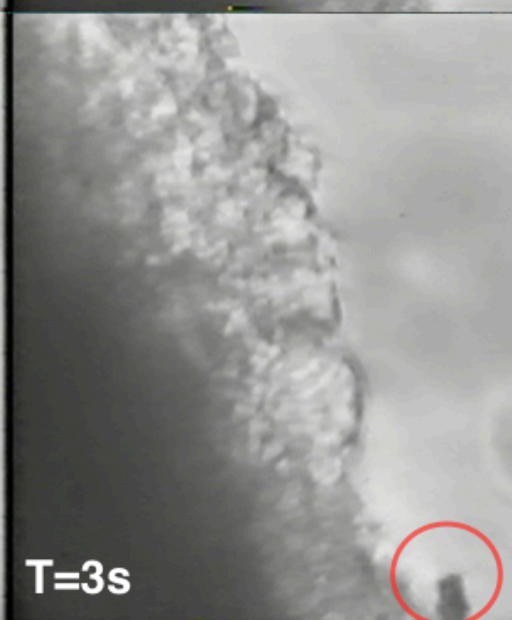

Figure 2. : Carbon particle being propelled by ciliated epithelium in vitro. Still screens captured from a video clip of ciliated uterine cells in a petri dish observed with an inverted microscope. Depicts how carbon particles are trapped in mucus (unstained) and moved by the cilia. Magnification is approximately 400x (unpublished data from Robert Causey).

Subsequent studies conducted by members of our research team (headed by Dr. Robert Causey) attempted to develop techniques for videoendoscopic detection of mucociliary clearance in the live 
mare. However, animal movement makes direct observation of active mucociliary clearance difficult, since neither the tissue nor the endoscope are immobilized. Therefore, to minimize movement, a technique was developed to secure an endoscope by introducing it through an endotracheal tube anchored by an inflatable cuff at the internal cervical os, the epithelium being exposed through a window cut in the tube (8). In this prior study (see preliminary data), microscopic movement of carbon particles placed on the cervical epithelium was observable. Movement of individual particles through stationary folds, past stationary points, in opposing directions, at different speeds, or with tumbling were deemed indicative of possible mucociliary currents. However, the carbon tended to aggregate and adhere to the epithelium, which may have obscured or interfered with microscopic movement. Also, because direct observation of beating cilia was not possible, it is still necessary to show that ciliary activity is responsible for these micro-currents.

In these early in vivo trials, carbon was infused onto the cervix of 3 mares and interaction between the carbon and the epithelium was recorded by high magnification-video endoscopy (8). Upon review, movement of the mare, including breathing, interfered with observation. Therefore, fixed landmarks were required to serve as a reference point to demonstrate translocation of carbon. However, the epithelial surface often lacked sufficient contrast to be a useful marker. Fortunately, adhered carbon provided a fixed background on which to observe movement of isolated free carbon particles. Therefore, movement of solitary particles past groups of stationary carbon and translocation in the space between two folds were deemed consistent with micro-currents possibly caused by ciliary motion. In addition, it appeared that some carbon fragments were tumbling (Figure 3) when they contacted the epithelial surface, which is consistent with the expected effect of ciliary action on a free particle. The movement of carbon particles relative to each other or past anatomical landmarks was therefore an observation that demonstrated micro-currents across the epithelium (Figure 4), and the 
tumbling of carbon particles approaching the epithelial surface potentially indicates that ciliary action is responsible for these currents.
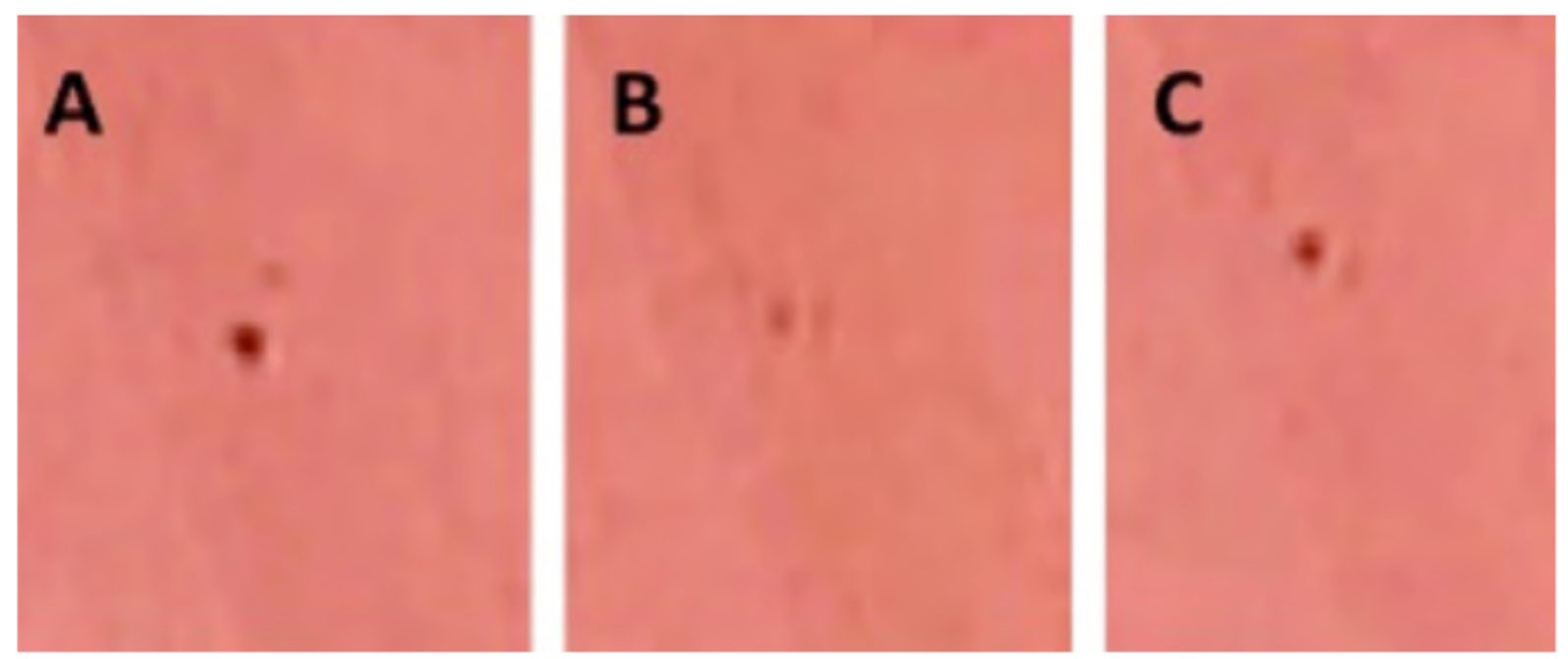

Figure 3. Carbon particle rotating on epithelium. Apparent rolling of a tile shaped carbon particle as it approaches the epithelium. In $A$ and $C$ the two alternate faces of the particle are seen while in $B$ the particle is seen "edge on".

These studies provided evidence of mucociliary clearance in the mare, but that carbon may not be the best material for such a demonstration. It was then proposed that non-adherent fluorescent microspheres and metallic powders (i.e. silver and gold) might be superior to carbon in assessment of equine cervical mucociliary clearance using high magnification video endoscopy. In addition, hemispherically coated bichromal microspheres might reveal micro-currents on the cervical epithelium through their visible rotation. For this reason, it became necessary to compare with carbon the feasibility of various other microparticles and microspheres in revealing mucociliary currents. 

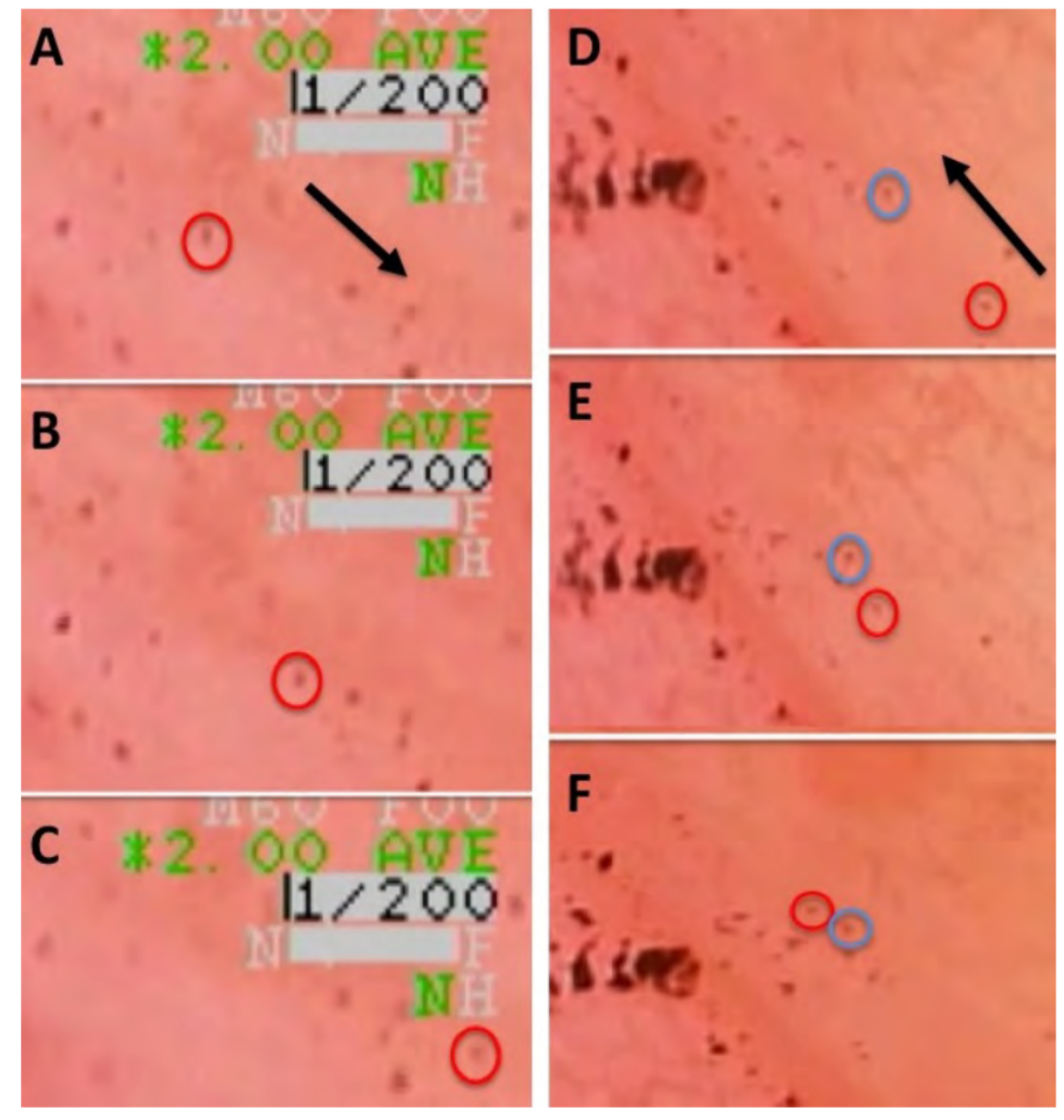

Figure 4. Translocation of carbon particles. Left Panel- A, B, C: Translocation of carbon particle (red circle) past stationary carbon adhered to epithelium. Right Panel-D, E, F: Different rates of carbon translocation of a fast particle (red circle) overtaking a slow particle (blue circle) both moving relative to stationary carbon. Arrow indicates direction of translocation in each panel

\subsection{Microspheres and Microparticles in Biology}

In considering which particles to evaluate for detecting mucociliary clearance in the equine uterus, particles need to meet the following criteria. First, they need to be non-toxic in the mare: the mare uterus can develop a dramatic inflammatory response to certain irritants, and it was necessary to pick particles which were likely to be non-irritating. Second, they needed to be visible against the pink 
mucosal surface. Third, they should be small enough that mucociliary clearance would likely be effective; therefore, a size of approximately $50 \mu \mathrm{m}$ or less seemed appropriate. Fourth, they should not aggregate into larger clumps; if they do then the resulting material may be too large for transport by mucociliary clearance. Fifth, they should be able to show rotation, which could be used as evidence for propulsion of one side of the particle by actively beating cilia. The following microparticles were felt to be possible candidates for use in videoendoscopy studies of mucociliary clearance in the mare.

\subsubsection{Gold}

One study examined the uptake and possible toxicity of gold particles in human leukemia cells. The gold particles were not cytotoxic and reduced the level of destructive oxidative species in the cell. However, when gold salts coated in a cationic material were used, they caused toxic effects, but only at an atomic concentration of $10 \mathrm{nM}$ or higher (21). Gold coated polystyrene spheres have been used in respiratory experiments involving mucociliary clearance. The spheres were used to track the speed of mucociliary clearance in tracheae excised from chicken embryos (16). To our knowledge gold has not been used to reveal mucociliary clearance in the reproductive tract.

\subsubsection{Silver}

A less costly option to gold, but with many of the same advantages, might be silver. A concern associated with the use of silver powder is its affinity to clump in an aqueous environment. In order to decrease this effect, applications of a dispersion agent are very common. One of these methods is to react silver nitrate over heat with ascorbic acid and gum arabic, followed by heating with ammonia. When the reaction is complete, the silver powder is filtered out and used for various studies (25). For example, this powder was used to track imaging in an electronic chip, and though it did reduce clumping, it raises concerns about irritation to an epithelial surface. The possibility of adding a non- 
irritating detergent to break the surface tension of these particles could lead to a viable option of in vivo studies of mucociliary clearance.

\subsubsection{Polyethylene Microspheres}

Fluorescent polyethylene microspheres may be an alternative to carbon in studies of mucociliary clearance. Polyethylene microspheres have been used for the demonstration of mucociliary activity in the respiratory epithelium of other species $(14,15,17)$. Advantages of fluorescent microspheres are that they are non-toxic, inert, and highly visible. It was one of the goals of the present study, therefore, to test such microspheres in mucociliary clearance experiments in the mare in vivo. In particular we wished to determine if there were an optimal microsphere diameter for this type of study, and if it were possible to observe microspheres in vivo using the lower power magnification of commonly available video-endoscopes. Available sizes included 1-5 $\mu \mathrm{m}$, and $70 \mu \mathrm{m}$.

In addition, the following special-application microspheres have other qualities that might confer specific advantages:

\subsubsection{Barium Coated microspheres}

The barium serves two purposes - one is to increase the weight of the particle so it is heavier than the fluid in which it is suspended. The particles are more likely to fall to the surface and be propelled along the tissue of the mare's uterus. The second purpose for using barium coated microspheres has been to increase visibility within the uterus of the mare. These spheres are commonly used to detect and diagnose problems in the digestive tract because of their high visibility within a body cavity when using radiographic techniques (3).

\subsubsection{Hemispherically Coated Bichromal Microspheres}

Hemispherically coated bichromal microspheres may be a novel technique to reveal ciliary activity by showing rotation of spheres. The bottom of the sphere moves in the direction of the current 
if propelled from below by cilia, whereas the bottom of a sphere rolling over a stationary surface might appear to be stationary, or move in the opposite direction. It can therefore be hypothesized that direction of rotation of the sphere may be used to predict the presence or absence of ciliary propulsion (figure 5). If results warrant, microspheres could then be used to study the effect of disease or therapy on mucociliary clearance rates, and may lead to a more economical method to evaluate mucociliary activity in a clinical setting.

A

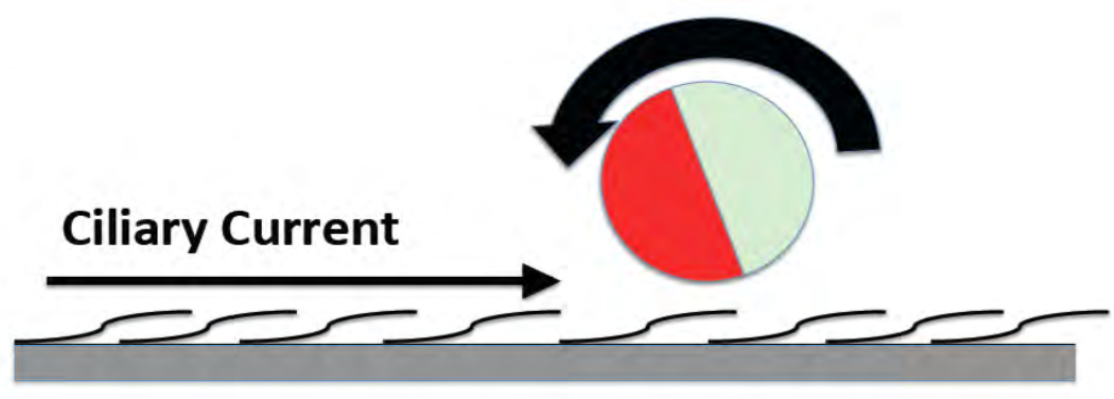

B

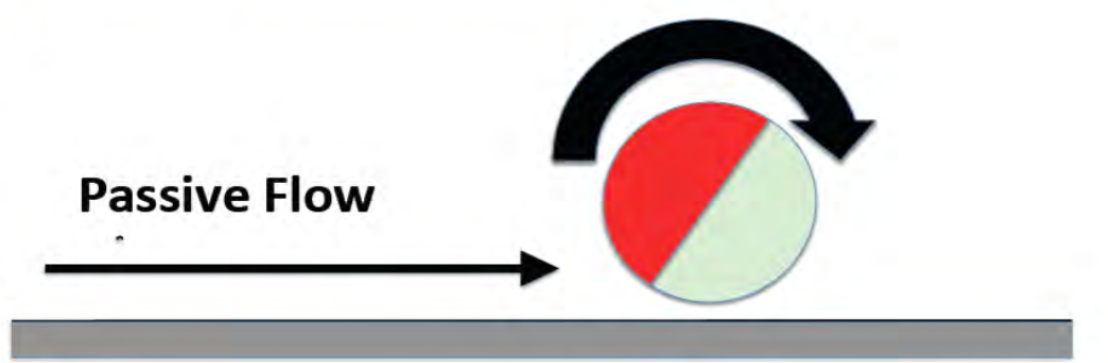

Figure 5: Prediction of two possible types of rotation that may be visible. Predicted rotation of hemispherically coated microspheres due to A) Ciliary current or B) passive flow.

\subsection{Objectives}

The overall objective of this study, therefore, was to determine the best particle for videoendoscopy to detect evidence of mucociliary clearance moving foreign material over the mare's cervix. It was hypothesized that polyethylene green microspheres 1 - $5 \mu \mathrm{m}$ and $70 \mu \mathrm{m}$ in diameter, 
would be superior to carbon in revealing micro-currents on the cervical epithelium and that $50 \mu \mathrm{m}$ hemispherically coated bichromal microspheres would display rotation. 


\section{CHAPTER 2}

\section{MATERIALS AND METHODS}

\subsection{In Vitro Assessment}

The following particles were studied by in vitro analysis: silver and gold powder, 1-5 $\mu \mathrm{m}$ green fluorescent spheres, $70 \mu \mathrm{m}$ green fluorescent microsphere, and $50 \mu \mathrm{m}$ white fluorescent barium coated microspheres (Cospheric ${ }^{\circledR}$, Santa Barbara, CA).

One mg of each particle was placed into separate wells of a 96-well plate. Each well then received $250 \mu \mathrm{L}$ of distilled water and was viewed under an inverted microscope (Amscope ${ }^{\circledR}$ Irvine, CA) and video recorded. Current was created to simulate motion of mucosal fluid in the uterus created by the contraction of the uterus. This was simulated by repeatedly aspirating and expelling the liquid with a $10 \mu \mathrm{L}$ pipette to generate micro currents. Detergent $(1 \mu \mathrm{L})$ was added to disrupt the surface tension and better distribute the particles. Recordings of each session were later observed and assessed for visibility, degree of clumping, and mobility of each kind of sphere.

The next portion of the in vitro study was to observe the particles in a six-well plate with an endoscope, the larger wells being required to accommodate the endoscope. Into each well, $2 \mathrm{mg}$ of each particle was submerged in $5 \mathrm{~mL}$ of distilled water in separate wells. The $1-5 \mu \mathrm{m}$ green microspheres, $70 \mu \mathrm{m}$ green microspheres, $50 \mu \mathrm{m}$ barium microspheres also received $10 \mu \mathrm{L}$ of Tween 20 detergent to aid dispersion. Current was created in each well by using a $1 \mathrm{~mL}$ pipette. Each well was video recorded using high-magnification video endoscopy for 5 minutes. Recordings were reviewed and particles assessed for visibility, their degree of clumping, and their mobility. The well containing a mixture of all particles was also observed for how the particles interacted with one another (Table 1).

To test for the suitability of premixing and storing aliquots of particle suspensions, particle mixtures were left in their wells and frozen overnight. They were then thawed after 24 hours and 
viewed with high-magnification video endoscopy and assessed for any possible degradation, such as cracks or fracturing.

Table 1: Assessment guidelines of particles during microscopic and endoscopic portions of the in vitro study. Particles received scores based on their visibility and mobility ( 1 if yes, 0 if no), and aggregation (zero represents no aggregation, while 4, 3, 2, 1 represent $100 \%, 75 \%, 50 \%, 25 \%$, of the visible microparticles clumping together, respectively.)

Criterion Results

Visibility

Aggregation

Mobility
1 or 0

$0-4$

1 or 0

\subsection{Particle Solution Preparation}

Different suspensions of particles were made to optimize the amount of each particle. Mare one received a single dose mixture of $5 \mathrm{mg}$ of the $1-5 \mu \mathrm{m}$ green microspheres, $1 \mathrm{mg}$ of carbon, and $2 \mathrm{~mL}$ of distilled water. Mare two received a single dose of $1 \mathrm{mg}$ of the $50 \mu \mathrm{m}$ bichromal microspheres, $1 \mathrm{mg}$ of the $70 \mu \mathrm{m}$ green microsphere, $1 \mathrm{~mL}$ of distilled water, and $10 \mu \mathrm{l}$ of Tween 20 detergent. Mares three, four, and five received varying doses (depending on the amount of edema, and possible irritation) with 4 pre-prepared suspensions as follows: two syringes with suspension one: $10 \mathrm{mg}$ of the $1-5 \mu \mathrm{m}$ green microspheres, $10 \mathrm{mg}$ of carbon, and $2 \mathrm{~mL}$ of distilled water; and two syringes with suspension two: $10 \mathrm{mg}$ of the $70 \mu \mathrm{m}$ green microspheres, $10 \mathrm{mg}$ of the bichromal microspheres, $2 \mathrm{~mL}$ of distilled water, and $10 \mu \mathrm{L}$ of Tween 20 detergent. 


\subsection{Videoendoscope}

A videoendoscope (Fujifilm, Wayne, NJ; EG-250WR5) was attached to a high-definition endoscopy digital video processor with FICE (flexible spectral imaging color enhancement) and a light source (Fujifilm, Wayne, NJ; EPX-4440HD with FICE). The video processor was than connected to a television monitor, as well as a laptop computer (Apple Macbook, Suzhou, China.) The analog output of the video processor was connected to a laptop using an Elgato video capture (Elgato, Munich, Germany; 10020840) in order to convert the file to a compatible digital format.

\subsection{Mare Preparation:}

This trial was conducted during July and August of 2017. Because the cervix is easier to examine while mares are in estrus, cervical mucociliary clearance was assessed by high-magnification video endoscopy in 5 estrous Standardbred mares with dominant follicles of diameter $30 \mathrm{~mm}$ or greater. Follicle size was determined by transrectal ultrasonography of estrous mares. All mares were restrained in examination stocks for transrectal ultrasonography and endoscopy.

Mares' tails were wrapped with a soft bandage. Sterile preparation of the perineal region using generic betadine scrub was followed by a water rinse to prevent the betadine from entering the vaginal canal. Sedation ( $5 \mathrm{mg}$ of detomidine IV) was given prior to the start of experimental examination in order to reduce movement. Using a sterile glove and sterile lubricant (First Priority Inc, Elgin, IL; NDC \#58829-200-05) a $14 \mathrm{~mm} \times 52 \mathrm{~cm}$ endotracheal tube (Jorgensen, Loveland, CO; \#J835Z) was inserted and anchored to the internal cervical os (internal opening of the cervix) by an inflatable cuff. A $1 \mathrm{~cm} \times 3 \mathrm{~cm}$ window (with edges smoothed) was previously cut in the endotracheal tube, with the long axis oriented longitudinally, to allow the folds of the cervix to flow into the tube. This cut was made with a scalpel and the edges smoothed with a butane flame. 
A suspension of the microspheres and carbon was then deposited on the cervical epithelium using a catheter passed through the endoscope. High - magnification video endoscopy sessions were then recorded for $10-20$ minutes.

\subsection{In Vivo Video Analysis:}

Following examinations, recordings were reviewed. Portions of the videos with a clear view of the epithelium and particles, at a magnification of 200X or greater, and lasting an observable amount of time (determined to be two seconds or greater) were logged for each video. Within each video segment, each type of particle received a single score ( 1 or 0 ) for the presence or absence in the video segment of the following observations for each particle: particle visibility, clumping, rotation, or movement (i.e. movement past a fixed point of immobilized carbon, two particles translocated at different speeds or in different directions or past a fixed anatomical landmark, such as capillary branch point). Once numerical scores were added, they were then divided by the total number of video segments in the recording to determine the percent of segments which contained the observation in question for each type of microparticle (e. g. percentage of segments containing carbon movement). The percentages were assigned a score as follows: $0 \%=0 ; 1 \%$ to $25 \%=1 ; 26 \%$ to $50 \%=2 ; 51 \%$ to $75 \%=3$; and $76 \%$ to $100 \%=$ 4. Scores were ordered such that the higher the number the more desirable the particle. Median total scores were then analyzed by the Kurskal-Wallis test to find a statistical difference between using different particles. 


\section{CHAPTER 3}

\section{RESULTS}

\subsection{In Vitro}

The various microparticles were analyzed by videomicroscopy and videoendoscopy in vitro to determine their suitability for in vivo use in the horse. The gold powder had a distinctive color and reflective property with large granules which were highly visible in fluid. However, the gold particles exhibited clumping and aggregated on the bottom of the wells when viewed both under the inverted microscope and with the endoscope. When a water current was applied, the gold remained immobile. Silver powder exhibited a high degree of clumping. In comparison to the gold, the particles of silver were much smaller and as a result more particles were stimulated by the current applied to the dish. Due to the large degree of clumping of gold and silver particles they were considered unsuitable and excluded from subsequent experiments.

The 1 - $5 \mu \mathrm{m}$ green fluorescent microspheres were difficult to see due to their size. There was no binding to other microspheres, and they largely appeared to be dispersed freely in the solution. (Table 2). When a water current was applied these spheres moved freely throughout the solution. They were chosen for the next phase of the experiment due to their close proximity in size to bacteria. If cilia are present then the viewer might be able to see each individual sphere interacting with the cilia as it moves through the uterus.

The $70 \mu \mathrm{m}$ green fluorescent microspheres scored high on visibility. There was no significant clumping among the spheres. They did however appear to sit on the surface of the distilled water, for which reason $1 \mu \mathrm{L}$ of Tween 20 was added to break the surface tension. This allowed for the freeflowing motion of the submerged spheres. 
The barium spheres were not easily visible in solution unless a black background was placed under the 96-well and 6-well plates. The barium spheres did not clump in solution but Tween 20 needed to be added to allow for dispersal. The barium spheres did not sink in the water as expected, their density being relatively close to water. The barium spheres appeared mobile and traveled in waves following the current. Due to their low scoring visibility, these spheres were not used for the in vivo part of the experiment.

Table 2: Assessment of particles during microscopic and endoscopic portions of the in vitro study. Particles received scores based on their visibility and mobility ( 1 if yes, 0 if no), and aggregation (zero represents no aggregation while 4, 3, 2, 1 represent $100 \%, 75 \%, 50 \%, 25 \%$, of the visible micro-particles clumping together, respectively.)

\begin{tabular}{ccccccc} 
Criterion & Gold & Silver & $\begin{array}{c}\mathbf{5 0} \boldsymbol{\mu \mathrm { m } \text { Barium }} \\
\text { microspheres }\end{array}$ & $\begin{array}{c}\mathbf{1 - 5} \boldsymbol{\mu \mathrm { m }} \text { Green } \\
\text { microspheres }\end{array}$ & $\begin{array}{c}\mathbf{7 0} \boldsymbol{\mu m} \text { Green } \\
\text { microspheres }\end{array}$ & Carbon \\
\hline Visibility & 1 & 1 & 0 & 1 & 1 & 1 \\
Aggregation & 4 & 3 & 0 & 0 & 0 & 2 \\
Mobility & 0 & 0 & 0 & 1 & 1 & 1 \\
\hline
\end{tabular}

The mixture of particles (Figure 6) was performed to see any particle interactions. Particles were again scored for their visibility, aggregation with other particles, and mobility. However, for this portion of the experiment, a watch was kept on possible adverse reactions that could injure the mare, however, none were seen. 


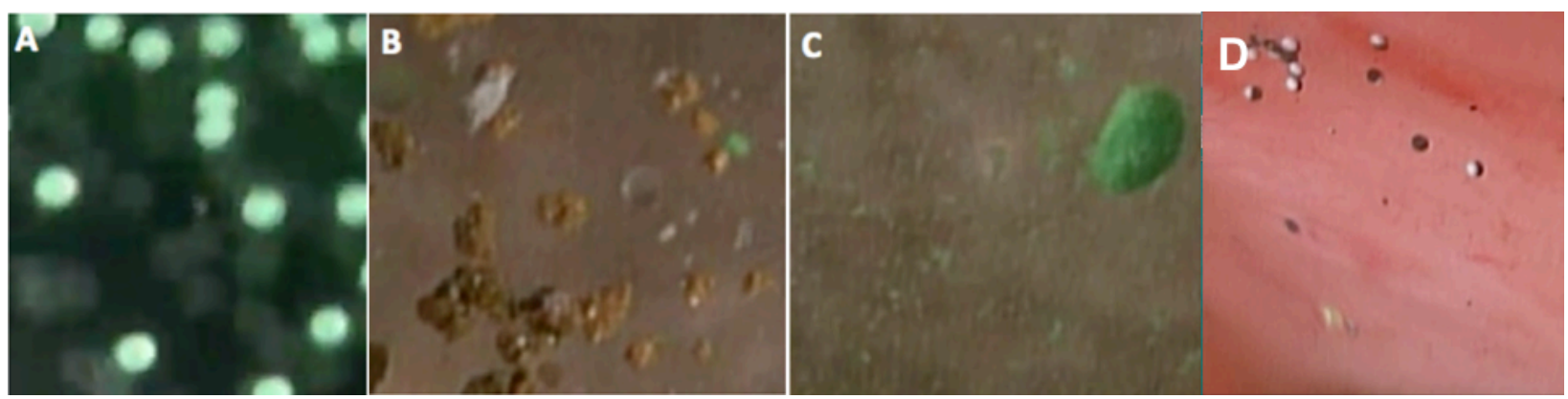

Figure 6: Appearance of several particles under videoendoscopy. Appearance under videoendoscopy of A: $70 \mu \mathrm{m}$ green microspheres, B: Silver, gold, barium impregnated $(50 \mu \mathrm{m})$ and green microspheres (1-5 $\mu \mathrm{m}$, and $70 \mu \mathrm{m}), \mathbf{C}: 1-5 \mu \mathrm{m}$ microspheres with clumping. D: Bichromal microspheres

\subsection{In Vivo}

The suspensions selected were two mixtures. The first was carbon and 1 - $5 \mu \mathrm{m}$ fluorescent green polyethylene microspheres, and $5 \mathrm{ml}$ of distilled water; the second was $70 \mu \mathrm{m}$ fluorescent green polyethylene microspheres, $50 \mu \mathrm{m}$ bichromal polyethylene microspheres, $5 \mathrm{ml}$ of water and $10 \mu \mathrm{l}$ of Tween 20 detergent. The first mare received one dose of $1 \mathrm{mg}$ of the $1-5 \mu \mathrm{m}$ microspheres and $1 \mathrm{mg}$ of carbon. The second mare received a single dose of $5 \mathrm{mg}$ of each particle used in this study. The third and fourth mares received two doses of $10 \mathrm{mg}$ of each particle used in this study. The fifth mare received one dose of $10 \mathrm{mg}$ of each particle used in this study. Video analysis results are shown in Table 3.

Overall, carbon was superior to all microspheres. Of the microspheres, the $1-5 \mu \mathrm{m}$ appeared to be the most suitable for in-vivo analysis. 
Table 3: Assessment of microspheres and carbon. Values in table represent median scores from all trials on a scale of $0-4$, from least to most desirable. Within rows, values without a superscript in common are statistically different $(P<0.05)$. $a$ is statistically different from $b$ and $c ; b$ is statistically different from $c$ and $a ; c$ is statistically different from $a$ and $b$.

\begin{tabular}{ccccc}
\hline Criterion & $\begin{array}{c}1-5 \mu \text { m Green } \\
\text { Microspheres } \\
(n=5)\end{array}$ & $\begin{array}{c}70 \mu \text { Green } \\
\text { Microspheres } \\
(n=4)\end{array}$ & $\begin{array}{c}50 \mu \text { michromal } \\
\text { Microspheres } \\
(n=4)\end{array}$ & Carbon \\
\hline Visibility & $3^{\mathrm{a}}$ & $3^{\mathrm{a}}$ & $2^{\mathrm{a}}$ & $4^{\mathrm{b}}$ \\
Aggregation & $3^{\mathrm{b}, \mathrm{c}}$ & $0.5^{\mathrm{a}}$ & $1^{\mathrm{a}, \mathrm{b}}$ & $4^{\mathrm{c}}$ \\
Motion & $2^{\mathrm{a}}$ & $2^{\mathrm{a}}$ & $2^{\mathrm{a}}$ & $4^{\mathrm{b}}$ \\
\hline Rotation & $0^{\mathrm{a}}$ & $0^{\mathrm{a}}$ & $0^{\mathrm{a}}$ & $2^{\mathrm{b}}$ \\
\hline Combined Median & $2^{\mathrm{a}}$ & $1^{\mathrm{a}}$ & $4^{\mathrm{b}}$ & $4^{\mathrm{a}}$ \\
\hline
\end{tabular}




\section{CHAPTER 4}

\section{DISCUSSION}

It was hypothesized that fluorescent microspheres $1-5 \mu \mathrm{m}$ and $70 \mu \mathrm{m}$ in diameter would be superior to metallic powders (i.e. silver and gold) and carbon in assessment of equine cervical mucociliary clearance using high magnification video endoscopy. This hypothesis was not supported due to data obtained during the in vitro portion of this study. It was also hypothesized that polyethylene microspheres the range of $1-70 \mu \mathrm{m}$, (including hemispherically coated bichromal microspheres of 50 $\mu \mathrm{m})$ would all be superior to carbon in revealing micro-currents on the cervical epithelium surface when observed by high magnification video-endoscopy in the live mare. The data from this portion did not support the hypothesis, either. We found that carbon may currently be the best option for observing mucociliary micro-currents on the cervical epithelium of the mare.

The in vitro experiments showed which particles were able to easily flow through the water, as well as how they would react with each other. Metallic particles appeared to be too heavy and did not flow in the solution. These also aggregated and were thought to be too large for cilia to move. Originally there were issues with proper dispersion throughout the solution, such that adding Tween 20 was tested to disrupt the surface tension of the water and allow for better dispersal, which it did. Particles were then able to move more freely through the solution. There was some aggregation of the 1 - $5 \mu \mathrm{m}$ fluorescent green microspheres but not enough to exclude them from the in vivo experiments.

Barium microspheres did not perform as expected. They were supplied in a clear vial that showed them as white, but when viewed in a solution they were nearly transparent, making them difficult to find and observe, which led to the decision to exclude them from the in vivo portion of this study. Bichromal microspheres were not viewed in vitro because they were not available at the time and were very expensive. They were the same material as the $70 \mu \mathrm{m}$ fluorescent green microsphere, with 
the only difference being the color. It was decided that these particles could be used in the in vitro study based on the data already collected.

Particles in the in vitro portions of this study were all scored according to the same criteria, however it was observed that when aggregation occurred it had little impact, either positively or negatively, due to an abundance of small particles remaining visible to show microcurrents. Consequently, any particles scoring a 0 in visibility or a 0 in mobility would not be suitable, but aggregation was not by itself sufficient to judge a particle unsuitable.

Two suspensions were used in vivo. The first was 1 - $5 \mu \mathrm{m}$ fluorescent green polyethylene microspheres, carbon, and $5 \mathrm{ml}$ of distilled water, the second being carbon with $70 \mu \mathrm{m}$ fluorescent green polyethylene microspheres, $50 \mu \mathrm{m}$ bichromal polyethylene microspheres, $5 \mathrm{ml}$ of water and $10 \mu \mathrm{l}$ of Tween 20 detergent. Varying amounts of particles were used in the first two examinations of the study to determine the optimal amount needed for observation. While $1 \mathrm{mg}$ of each particle was sufficient for observation, the likelihood of finding particles was greatly improved by using two doses of $10 \mathrm{mg}$ (a total of $20 \mathrm{mg}$ of each particle per mare).

Carbon exhibited the highest total score, and the determining factor appeared to be the ability of carbon to reveal rotation of particles as small as approximately $5 \mu \mathrm{m}$, probably through their irregular shape distorting the meniscus leading to repeating flashes of light (Figure 7). Rotation could not be seen in any of the polyethylene microspheres, except for the bichromal microspheres. However, the latter rarely displayed rotation, possibly due to their large size and possibly being immobilized by mucus. 

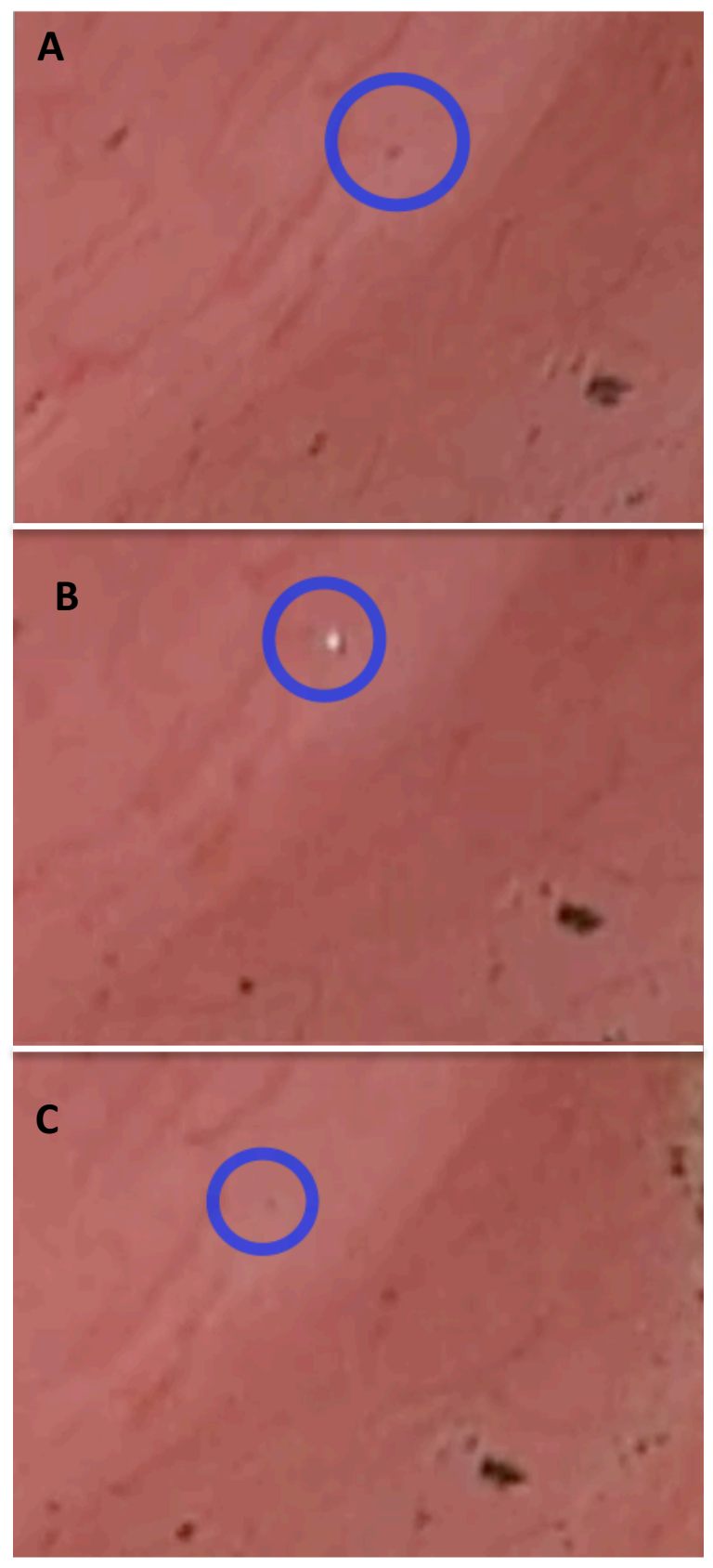

Figure 7: Particle rotation giving rise to flashes of light. Apparent rotation captured in three images over approximately one second $[A, B, C]$, probably due to the irregular shape of carbon distorting the meniscus leading to repeating flashes of light $[B]$. 
Without aggregation, the 1 - $5 \mu \mathrm{m}$ microspheres would not have been visible, individual particles being too small to be seen and the $1-5 \mu \mathrm{m}$ polyethylene green microspheres were difficult to see on their own due to their small size. When clumped together it became clear that they may not be able to adequately show mucociliary micro-currents, but they were observed to be extremely useful at helping visualize the mucus present at lower magnification (Figure 8), almost as if they were acting as a stain. This was often helpful in seeing gross movement of the mucus and gave superior contrast for viewing other particles. 


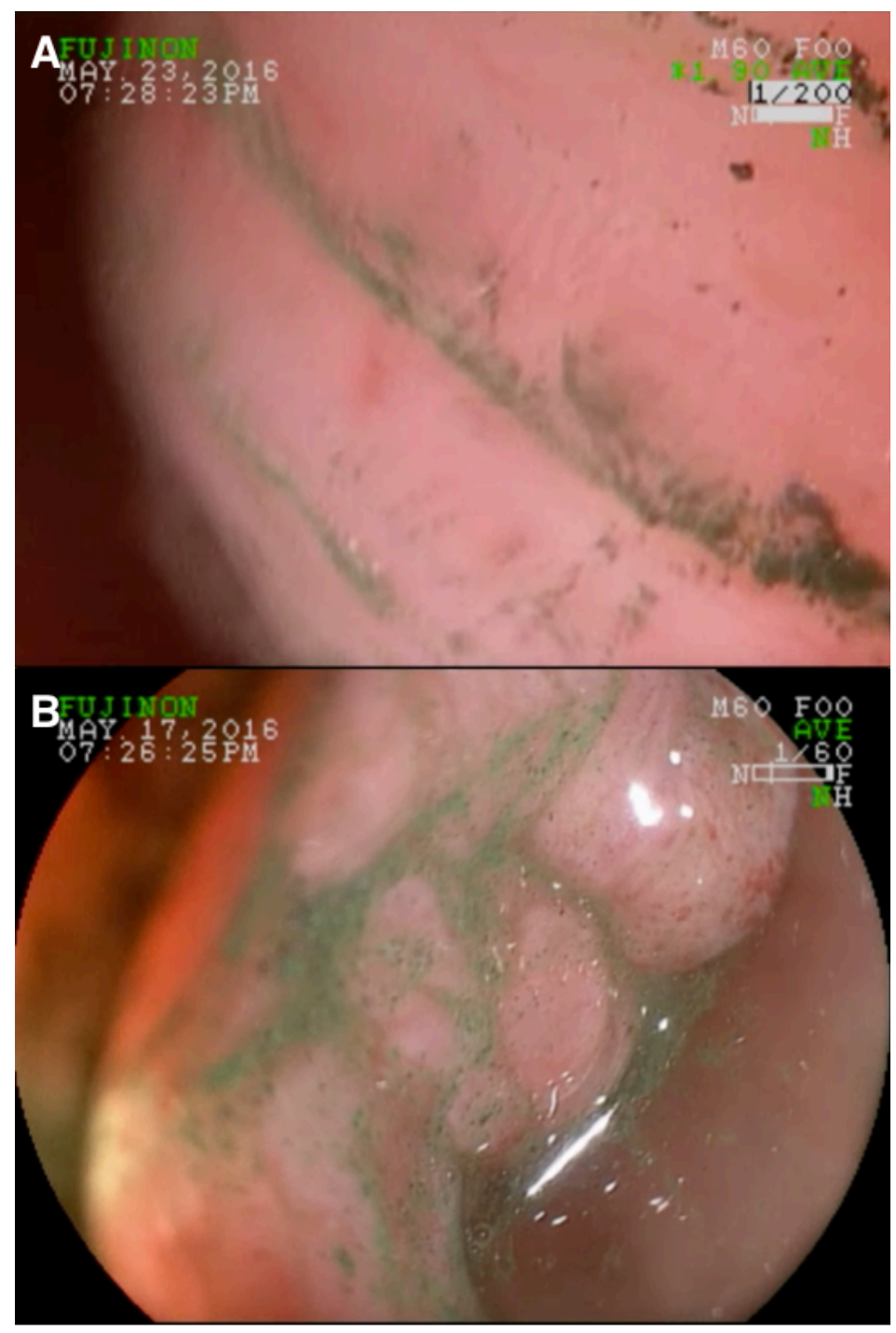

Figure 8: Mucus staining effect of 1-5 $\mu \mathrm{m}$ fluorescent green polyethylene microspheres. A) Microscopic view of $1-5 \mu \mathrm{m}$ polyethylene green microspheres revealing a mucus cluster and the folds in the cervix. Mucus can be seen as a greenish fluid in which other particles are trapped. B) Macroscopic image of 1$5 \mu \mathrm{m}$ polyethylene microspheres revealing mucus clusters and folds they travel through on the cervix.

The bichromal spheres were much easier to view on the epithelial surface. Unfortunately, the bichromal spheres failed to show the rotation associated with ciliary movement. This observation may 
be due to the particles being too large. Movement and rotation were typically seen with smaller particles of roughly $10 \mu \mathrm{m}$ or less.

Upon examination of videos, interesting observations were made, such as particles moving slowly in a mucus blanket, consistent with descriptions of mucociliary clearance in the respiratory tract. In addition, blood cells flowing through capillaries could be discerned, along with the apparent flow in surface lymphatic vessels (Figure 9). Blood vessels and lymphatics (vessels appearing too small for passage of a red blood cell) were often used as fixed landmarks to visualize translocation of particles. In some clips, it was observed that different regions of the mucus layer were moving independently, possibly due to different sections of cilia propelling separate mucus "sheets" (Figure 10). Gross movement of particles was not examined closely, but revealed interesting features when stained with the 1 - $5 \mu \mathrm{m}$ polyethylene microspheres. Gross movement was originally expected to be on a large scale, due to uterine contractions and the abdominal press.

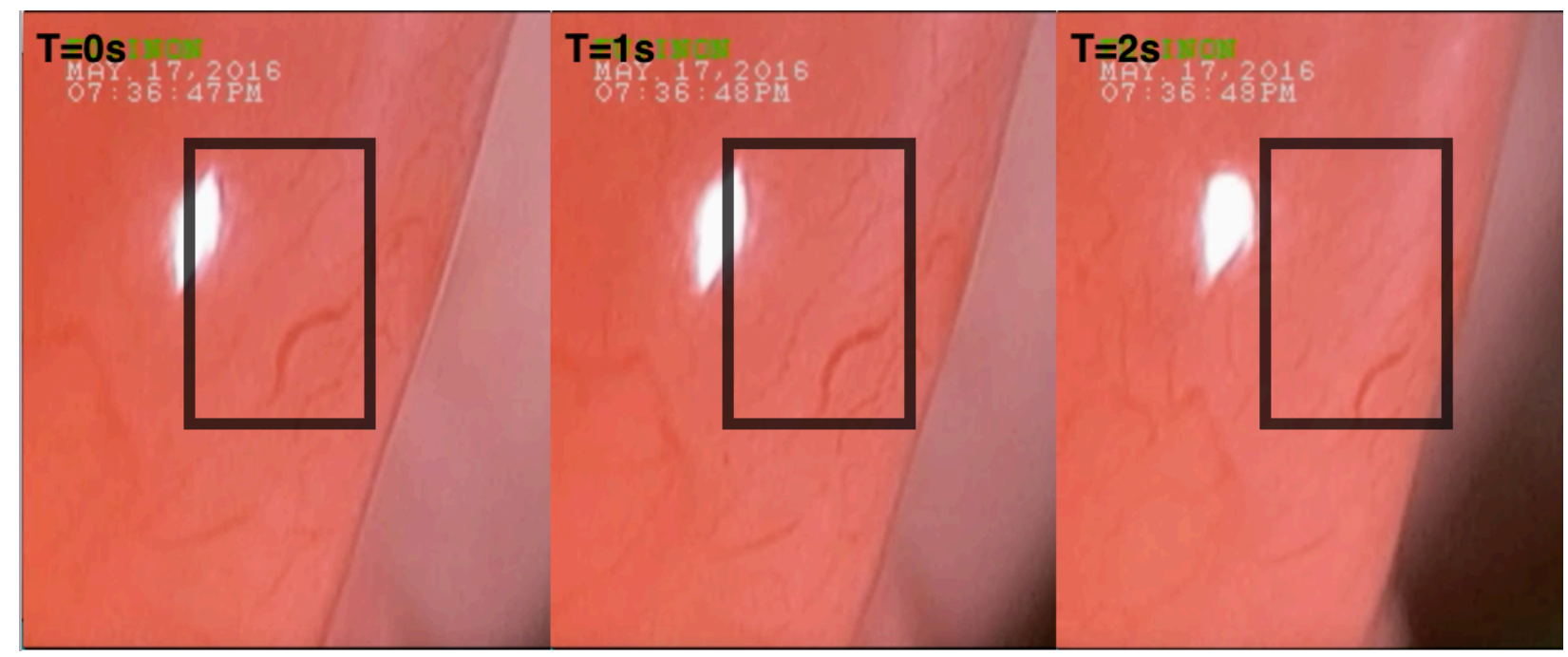

Figure 9: Fluid flow through blood and lymphatic vessels. From the left panel to the right panel $[T=0 s, 1 s$, $2 \mathrm{~s}]$, there is a visible change in the volume of fluid inside the vessels. 


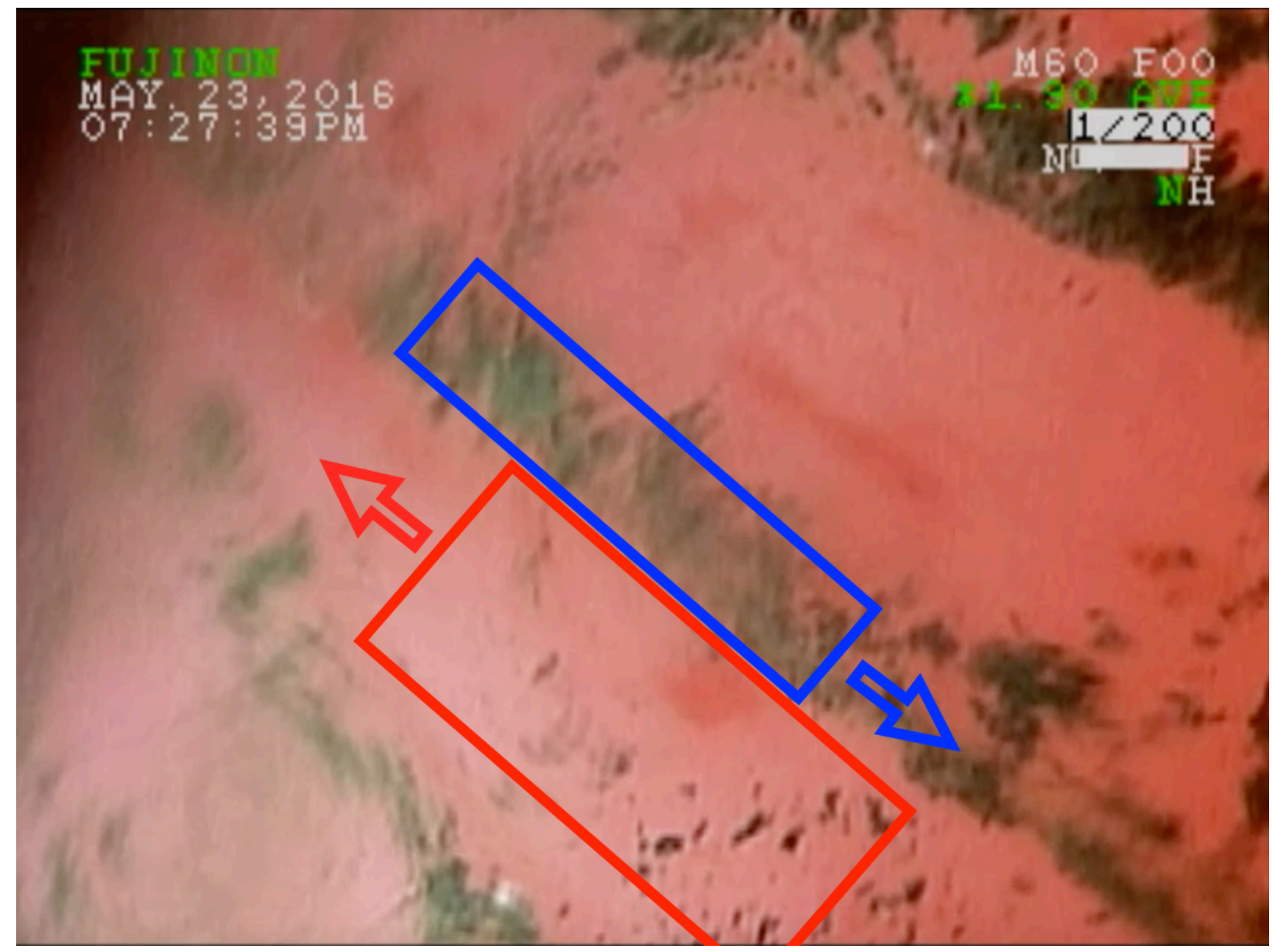

Figure 10: Mucus sheets moving in opposing directions, in an alternating pattern. Alternating sheets of mucus moving in different directions. Red Box: Sheet of mucus moving to the left. Blue Box: Sheet of mucus moving to the right.

An additional interesting finding that was observed grossly over 10 - 30 minutes was that the epithelial surface of the cervix was able to fully clear the particles. Future studies should include a more detailed examination of the macroscopic paths taken by these particles $t$ was also observed that, over an entire section of the epithelium, movement was at a constant rate in the opposite direction to gravity, a finding which could be explained by ciliary motion (Figure 11). 


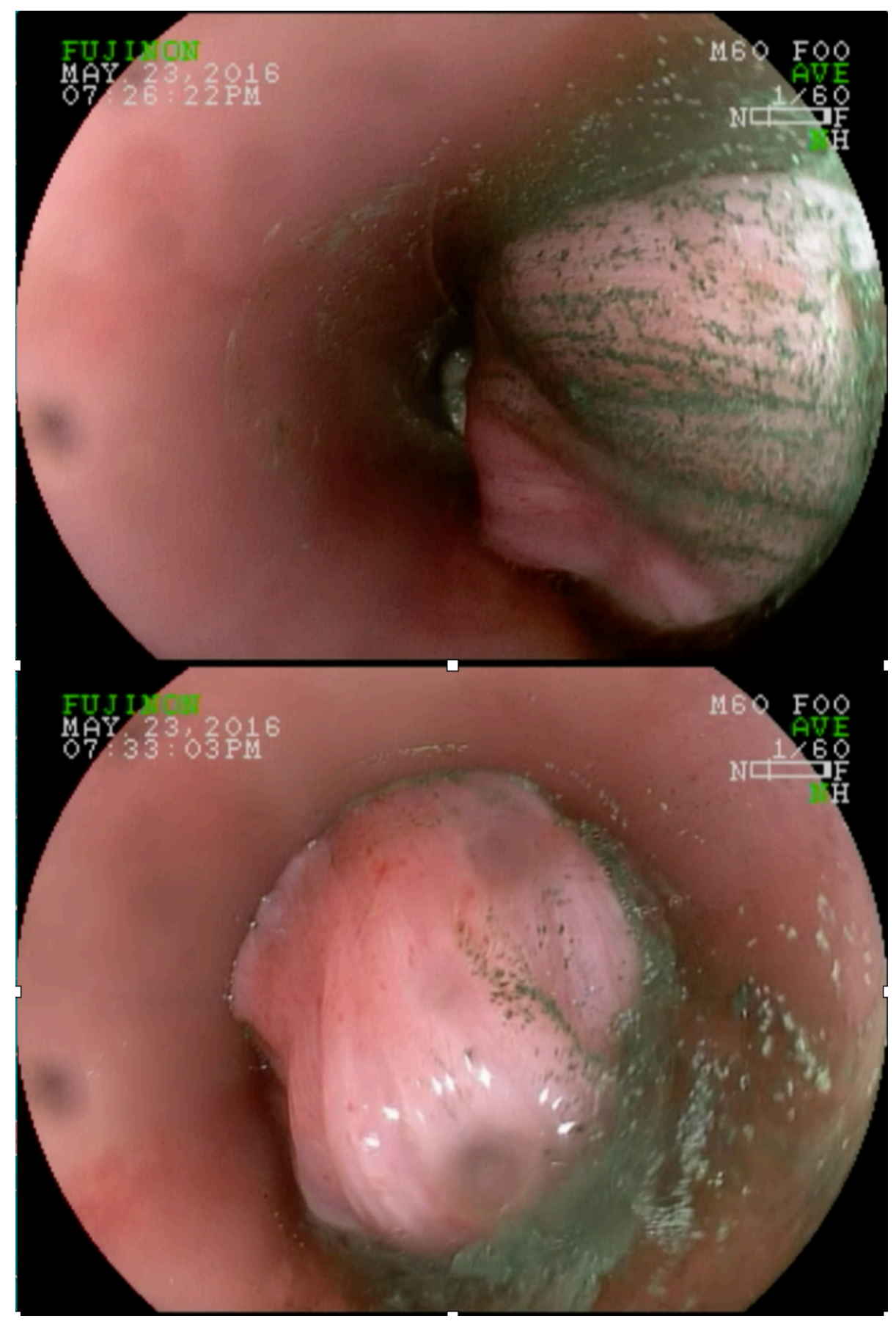

Figure 11: Self-clearing of the cervical epithelium in under 10 minutes. Macroscopic view of the cervical epithelium at application of particles (top panel) and seven minutes post-application (bottom panel) showing self-clearing. 


\section{CHAPTER 5}

\section{CONCLUSION}

This study has provided additional evidence for the presence of mucociliary clearance in the mare's cervix. Although the purpose of this study was to find a particle superior to carbon for visualizing mucociliary clearance, carbon seems the best particle to reveal microscopic movement, and 1 - $5 \mu \mathrm{m}$ polyethylene microspheres for gross movement. Carbon can apparently show rotation by distortion of the meniscus leading to flashes of reflected light. Future studies that will be conducted include chromeoendoscopy and the inclusion of vital stains to reveal additional features.

Based on these results, a mixture of $10 \mathrm{mg}$ carbon and $10 \mathrm{mg}$ of 1 - $5 \mu \mathrm{m}$ polyethylene microspheres in $1 \mathrm{~mL}$ of water may be the best available particle mixture for this type of study, and may be helpful as a diagnostic test in identifying focal areas of the cervix and endometrium with pathologic

foci. The goal of all equine reproductive mucociliary research is to improve upon current understanding of equine uterine defenses in order to improve treatment and diagnosis of equine infertility. 


\section{REFERENCES}

[1] Bain AM. The role of infection in infertility in the Thorough-bred mare. The Veterinary Record 1996;78:168-175.

[2] Brody SL. Sensory Functions of Motile Cilia and Implication for Bronchiectasis. Frontiers in Bioscience 2012;S4:3:1088-1098.

[3] Burbidge HM, Robertson ID. Pros and cons of barium-impregnated polyethylene spheres in gastrointestinal disease. Veterinary Clinics of North America Small Animal Practice 2000;2:449-465.

[4] Canissol F, Stewart J, Coutinho da Silva MA. Endometritis: Managing Persistent Post-Breeding Endometritis. Veterinary Clinics of North America Equine Practice 2016;32:465-480.

[5] Causey R. Pathogenesis of equine endometritis due to Streptococcus zooepidemicus. Ph.D. Thesis, Louisiana State University; 1995.

[6] Causey R, Ginn P, Katz B, Hall B, Anderson K, LeBlanc M. Mucus production by endometrium of reproductively healthy mares and mares with delayed uterine clearance. Journal of Reproduction and Fertility Supplement 2000;56:333-339.

[7] Causey R. Mucus and the Mare: How little we know. Journal of Theriogenology 2007;68:3:386-394.

[8] Causey R, Christian E, Hawkes M, Diver A, Stokes M. Examination of the equine cervix by high magnification video-endoscopy. Journal of Clinical Theriogenology Supplement 2016;8:345.

[9] Dimock WW, Edwards PR. Pathology and bacteriology of the reproductive organs of mares in relation to sterility. Kentucky Agricultural Experiment Station Bulletin (Research Bulletin) 1928;286:157-237.

[10] Dixon PM. Respiratory mucociliary clearance in the horse in health and disease, and its pharmaceutical modification. The Veterinary Record 1992;131:229-235.

[11] Gardiner M. The Importance of Cilia. Howard Hughes Medical Insititue Bulletin 2015;18:33-36.

[12] Ginther O. Reproductive Biology of the Mare. Equiservices, Cross Plains WI, USA, 1992.

[13] Gray J. Ciliary Movement., Cambridge University Press, London, 1928.

[14] Inoue D, Furubayashi T, Ogawara K, Kimura T, Higaki K, Katsumi H, Sakane T, Yamamoto A, Higashi $\mathrm{Y}$. In vitro evaluation of nasal mucociliary clearance using excised rat nasal septum. Biological and Pharmaceutical Bulletin 2012;35:889-894. 
[15] Jacob S, Zhu Y, Kraft R, Cotto C, Carmical JR, Wood TG, Enkhbaatar P, Herndon DN, Hawkins HK, Cox RA. Physiologic and molecular changes in the tracheal epithelium of rats following burn injury. International Journal of Burns and Trauma 2015;5:36-45.

[16] Kirch J, Guenther M, Doshi N, Schaefar U.F., Schneider M, Mitragori S, Lehr M. Mucociliary clearance of micro- and nanoparticles is independent of size, shape and charge - an ex vivo and in silico approach. Journal of Controlled Release 2012;159:128-134.

[17] Lai Y, Dilidaer D, Chen B, Xu G, Shi J, Lee RJ, Cohen NA. In vitro studies of a distillate of rectified essential oils on sinonasal components of mucociliary clearance. American Journal of Rhinology and Allergy 2014;28:244-248.

[18] LeBlanc MM, Neuwirth L, Jones L, Cage C, Mauragis D. Dfferences in uterine position of reproductively normal mares and those with delayed uterine clearance detected by scintigraphy. Theriogenology 1998; 50:49-54.

[19] Louvi A, Grove EA. Cilia in the CNS: the quiet organelle claims center stage. Neuron 2011;69:10461060.

[20] Martin, E, Hine, R. A Dictionary of Biology. Oxford University Press, Cary, NC, USA, 2008.

[21] Murphy CJ, Gole AM, Alkilany AM, Goldsmith EC, Baxter SC. Gold nanoparticles in biology: beyond toxicity to cellular imaging. Accounts of Chemical Research 2008;41:1721-1730.

[22] Peterson FB, McFeely RA, David JSE. Studies on the pathogenesis of endometritis in the mare. Proceedings of the American Association Equine Practitioners 1969;15:279-287.

[23] Raidal SL, Love DN, Bailey GD. Effects of posture and accumulated airway secretions on tracheal mucociliary transport in the horse. Australian Veterinary Journal 1996;73:45-49.

[24] Scholey JM. Intraflagellar transport motors in cilia: moving along the cell's antenna. Journal of Cell Biology 2008;180:23-29.

[25] Songping W, Shuyuan M. Preparation of ultrafine silver powder using ascorbic acid as reducing agent and its application in MLCI. Materials Chemistry and Physics 2005;89:423-427.

[26] Troedsson MH, Woodward EM. Our current understanding of the pathophysiology of equine endometritis with an emphasis on breeding-induced endometritis. Reproductive Biology 2016;16:8-12.

[27] Watson ED. Post-breeding endometritis in the mare. Animal Reproduction Science 2000;60:221232.

[28] Williamson P, Munyua S, Martin R, Penhale W.J. Dynamics of the acute uterine response to infection, endotoxin infusion and physical manipulation of the reproductive tract in the mare. Journal of Reproduction and Fertility 1987;35:317-325. 
[29] Willoughby RA, Ecker GL, McKee L, Riddolls LJ. Use of scintigraphy for the determination of mucociliary clearance rates in normal, sedated, diseased and exercised horses. Canadian Journal of Veterinary Research 1991;55:315-320. 


\section{APPENDIX: Individual in vivo score tables}

Appendix: Individual assessment of microspheres and carbon according to 4 criteria. Values in table represent scores on a scale of 0 - 4 , from least to most desirable.

$0=$ Present in $0 \%$ of video segments

$1=$ Present in $1-25 \%$ of video segments

$2=$ Present in $26-50 \%$ of video segments

$3=$ Present in $51-75 \%$ of video segments

$4=$ Present in $76-100 \%$ of video segment

Table 4: Mare 1 (Sara)

\begin{tabular}{|c|c|c|c|c|}
\hline Criterion & $\begin{array}{l}1 \text { - } 5 \mu \mathrm{m} \text { Green } \\
\text { Microspheres }\end{array}$ & $\begin{array}{l}70 \mu \mathrm{m} \text { Green } \\
\text { Microspheres }\end{array}$ & $\begin{array}{c}50 \mu \mathrm{m} \text { Bichromal } \\
\text { Microspheres }\end{array}$ & Carbon \\
\hline Visibility & 2 & - & - & 4 \\
\hline Aggregation & 2 & - & - & 4 \\
\hline Motion & 2 & - & - & 3 \\
\hline Rotation & 0 & - & - & 1 \\
\hline
\end{tabular}


Table 5: Mare 2 (Blisstex)

\begin{tabular}{|c|c|c|c|c|}
\hline Criterion & $\begin{array}{l}1 \text { - } 5 \mu \mathrm{m} \text { Green } \\
\text { Microspheres }\end{array}$ & $\begin{array}{l}70 \mu \mathrm{m} \text { Green } \\
\text { Microspheres }\end{array}$ & $\begin{array}{c}50 \mu \mathrm{m} \text { Bichromal } \\
\text { Microspheres }\end{array}$ & Carbon \\
\hline Visibility & 3 & 2 & 2 & 4 \\
\hline Aggregation & 0 & 1 & 1 & 2 \\
\hline Motion & 2 & 2 & 2 & 4 \\
\hline Rotation & 1 & 0 & 0 & 2 \\
\hline
\end{tabular}

Table 6: Mare 3 (Laney)

\begin{tabular}{|c|c|c|c|c|}
\hline Criterion & $\begin{array}{l}1 \text { - } 5 \mu \mathrm{m} \text { Green } \\
\text { Microspheres }\end{array}$ & $\begin{array}{l}70 \mu \mathrm{m} \text { Green } \\
\text { Microspheres }\end{array}$ & $\begin{array}{c}50 \mu \mathrm{m} \text { Bichromal } \\
\text { Microspheres }\end{array}$ & Carbon \\
\hline Visibility & 3 & 3 & 3 & 4 \\
\hline Aggregation & 3 & 1 & 1 & 4 \\
\hline Motion & 2 & 1 & 1 & 4 \\
\hline Rotation & 0 & 0 & 0 & 2 \\
\hline
\end{tabular}


Table 7: Mare 4 (Susie)

\begin{tabular}{|c|c|c|c|c|}
\hline Criterion & $\begin{array}{l}1 \text { - } 5 \mu \mathrm{m} \text { Green } \\
\text { Microspheres }\end{array}$ & $\begin{array}{l}70 \mu \mathrm{m} \text { Green } \\
\text { Microspheres }\end{array}$ & $\begin{array}{c}50 \mu \mathrm{m} \text { Bichromal } \\
\text { Microspheres }\end{array}$ & Carbon \\
\hline Visibility & 4 & 3 & 2 & 4 \\
\hline Aggregation & 4 & 0 & 2 & 4 \\
\hline Motion & 4 & 2 & 2 & 3 \\
\hline Rotation & 0 & 0 & 1 & 2 \\
\hline
\end{tabular}

Table 8: Mare 5 (Gina)

\begin{tabular}{|c|c|c|c|c|}
\hline Criterion & $\begin{array}{l}1 \text { - } 5 \mu \mathrm{m} \text { Green } \\
\text { Microspheres }\end{array}$ & $\begin{array}{l}70 \mu \mathrm{m} \text { Green } \\
\text { Microspheres }\end{array}$ & $\begin{array}{c}50 \mu \mathrm{m} \text { Bichromal } \\
\text { Microspheres }\end{array}$ & Carbon \\
\hline Visibility & 3 & 3 & 2 & 4 \\
\hline Aggregation & 3 & 0 & 1 & 3 \\
\hline Motion & 2 & 2 & 3 & 4 \\
\hline Rotation & 0 & 0 & 0 & 2 \\
\hline
\end{tabular}




\section{BIOGRAPHY OF THE AUTHOR}

Melissa Hawkes was born in York, Maine on May 27, 1994. She was raised in Kittery, Maine and graduated from R.W. Traip Academy in 2012. She attended the University of Maine and graduated in 2016 with a Bachelor's degree in Animal Science. She entered the Animal Science graduate program at The University of Maine in the fall of 2016. After receiving her degree, Melissa will be applying to veterinary schools in order to begin her career in veterinary medicine. Melissa is a candidate for the Master of Sciences degree in Animal Science from the University of Maine in May 2018. 